\title{
REVISÃO: \\ Descrição de critérios utilizados atualmente para compor as listas de espécies ameaçadas e endêmicas
}

\author{
Bruno Senna Corrêa ${ }^{1}$, Júlio Neil Cassa Louzada ${ }^{2}$, Aloysio Souza de Moura ${ }^{3}$ \\ ${ }^{1}$ CEFET-MG - Campus IX Nepomuceno - Av. Monsenhor - Luiz de Gonzaga, 103 - Centro, Nepomuceno, MG, CEP: \\ 37250-000. bruno.senna@gmail.com \\ ${ }^{2}$ UFLA - Caixa Postal 37 CEP 37200-000, Lavras, MG Campus Universitário, DBio - Setor Ecologia. \\ jlouzada@dbi.ufla.br \\ ${ }^{3}$ UNILAVRAS - graduando em Ciências Biológicas pelo Centro Universitário de Lavras "UNILAVRAS”. Caixa \\ Postal 197, CEP 37.200.000, Lavras, MG. thraupidaelo@yahoo.com.br
}

\section{RESUMO}

Atualmente observa-se uma crescente perda da diversidade biológica nos principais Biomas e ecossistemas do planeta. A real dimensão desta perda é um parâmetro pouco conhecido pela população em geral. Normalmente são discutidos pontos isolados, sem argumentação e sem base científica, para se justificar o desaparecimento de algum taxa na natureza. Dessa forma, buscando padronizar os critérios para avaliar a real distribuição das espécies nos principais ambientes terrestres do planeta, discute-se neste trabalho os critérios científicos e mensuráveis estabelecidos pela União Mundial para a Natureza (IUCN). Valoriza-se dessa forma o esforço da organização que, associado a outras organizações internacionais (CI, WWF, NGS) e nacionais (SAVE Brasil, Pró-carnívoros) podem proporcionar bons resultados para manutenção e conservação da diversidade biológica.

Termos para indexação: perda de diversidade, impacto antrópico, desaparecimento de espécies

\section{Description of criteria used currently to compose the lists of threatened and endemic species}

\begin{abstract}
Currently it observes an increasing loss of biological diversity in the main Biomas and ecosystems of the planet. The real dimension of this loss is a parameter little known by the population in general. Normally isolated points are argued, without argument and scientific base, to justify the disappearance of some taxa in the nature. Of this form, searching to standardize the criteria to evaluate the real distribution of the species in main terrestrial environments of the planet, one argues in this work the scientific and measurable criteria established by the International Union for Conservation Nature (IUCN). The effort of the organization is valued of this form that, associated to other international organizations (CI, WWF, NGS) and national (SAVE Brazil, Pro-carnivores) can provide good resulted for maintenance and conservation of the biological diversity.
\end{abstract}

Terms for indexation: loss of diversity, human impact, disappearance of species 


\section{INTRODUÇ̃̃O}

A diversidade biológica de espécies nos biomas terrestres atenta para uma perda crescente de representantes. Entre as causas mais discutidas na comunidade científica para o Neotrópico, destacam-se a fragmentação gerada pela expansão agrícola, exploração de madeira, mineração, pecuária, entre outros.

A fragmentação gera alterações nos habitats naturais, modificando os nichos e o microclima dos ambientes (fatores abióticos e fatores bióticos), reduzindo assim a disponibilidade de recursos alimentares (qualidade e/ou quantidade), espaço e abrigo (Turner, 1996).

Paralelo a essa perda massiva de espécies animais e vegetais, observa-se a preocupação da comunidade científica no estabelecimento de critérios para avaliar a definição de regiões estratégicas (hotspots) e de considerável diversidade biológica nos Biomas.

O estabelecimento de critérios e estratégias visando a categorização dos taxa com algum grau de alteração é o objetivo deste trabalho, baseado nos princípios adotados pela União Mundial para a Natureza (IUCN).

\section{REFERENCIAL TEÓRICO}

Para classificar as espécies foram propostas categorias de ameaças baseadas em critérios adotados pela União Mundial para a Natureza (IUCN). Os critérios IUCN buscam evidências relacionadas ao tamanho, isolamento ou declínio populacional das espécies e extensão de suas áreas de distribuição. A partir desses dados, definidos os níveis de ameaça, considerando o uso dos critérios em escala regional, ou seja, área geográfica subglobal tal como um continente, país, estado ou província, as espécies são agrupadas conforme as categorias: Extinta, Extinta na natureza, Criticamente em perigo, Em perigo, Vulnerável, Quase Ameaçadas e Deficientes em Dados (figura 1). É importante destacar que os critérios são bastante específicos para inclusão das espécies nestas categorias, sendo portanto necessário um conjunto de dados complexos, com datas, pontos georreferenciados, caracterização dos ecossistemas, caracterização de áreas adjacentes, tipos de impactos, grau dos impactos, severidade e temporalidade dos impactos presentes. Para categorização das espécies nos diferentes níveis de ameaça são considerados os seguintes critérios conforme sumário das categorias e critérios IUCN (2001) ou critérios completo e critérios em escala regional, IUCN (2003):

$>$ Redução do tamanho da população;

> Variação na extensão da área de ocorrência ou da área de ocupação; Número de indivíduos maduros;

> Análise quantitativa mostrando a probabilidade de extinção na natureza em relação ao tempo ou ao número de gerações.

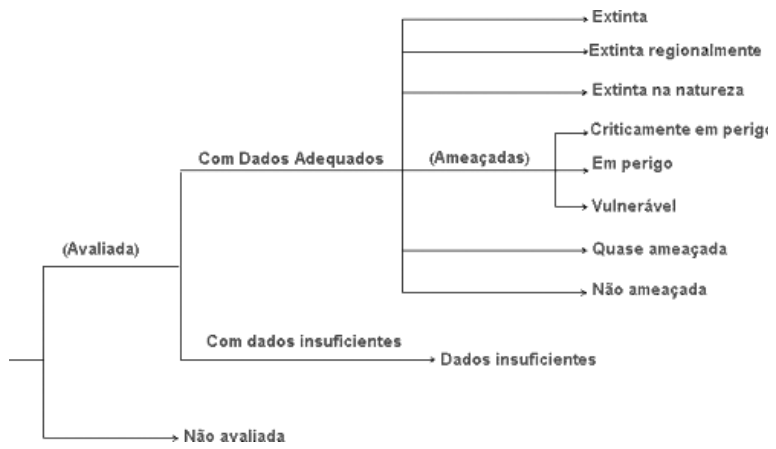

Figura 1: Esquema de classificação das categorias (Fonte: IUCN, 2001)

Dessa maneira, obtêm-se parâmetros para buscar inferências futuras sobre o destino da espécie estudada.

Abaixo segue o conceito para cada categoria, seguido da explicação e exemplos para cada categoria.

\section{Categorias:}

a) Extinta - Um táxon será considerado Extinto quando não há dúvidas de que o último indivíduo morreu. 
No contexto da categoria Extinta, é importante levantar a eficiência limitada das estratégias para a classificação das espécies de fauna e flora ameaçadas. Ambientes naturais nas áreas tropicais vem sofrendo processo gradual e intenso de fragmentação, seja para práticas agrícolas (soja, milho, café, cana de açúcar, feijão), seja para pecuária, seja para implementação de usinas hidrelétricas ou construção de cidades.

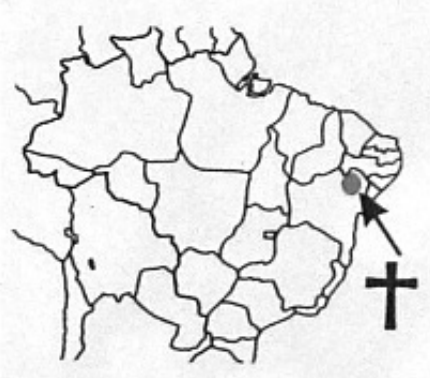

Figura 2: Distribuição de Cyanopsitta spixii (Fonte: Sigrist, 2005)

Esta última espécie, vivia nas baixadas com palmeiras (tucum, mucujá), margem de rio, escavava seus ninhos nos barrancos do rio Paraguai, nidificando também em ocos de árvore. No começo do século passado era comum ao longo do rio Paraná, perto dos Corrientes, Argentina; Região sul do Brasil ao longo do rio Paraná.

Recentemente a IUCN, mostra que 380 espécies se tornaram extintas na natureza, com um 371 espécies incluídas na lista de Extintas/ Em perigo. Estimativas científicas recentes indicam que o número de espécies que desaparecem diariamente é baixo. Entretanto, deve ser lembrado que a lista só registra espécies que estão certamente extintas, sendo que deve haver um número bem superior de extinções sem que sejam relatadas. Há no mínimo 6.522 espécies listadas como Em perigo. Sem esforços concentrados para registros confiáveis e acurados das espécies, muitas destas espécies irão ser adicionadas à lista de Extintas.

b) Extinta regionalmente - Um táxon será
Dentro dos critérios usados para classificação dos níveis de ameaça em escala regional, a categoria Extinta, pode ser empregada para representantes que certamente não existem mais na natureza. Um exemplo, no Brasil, é a ararinha-azul (Cyanopsitta spixii) (figura 2), no qual dos últimos três indivíduos conhecidos na natureza foram capturados e vendidos em 1988 e arara-cinza-azulada (Anodhorhynchus glaucus) (figura 3), extinta na natureza (Sick, 2001).

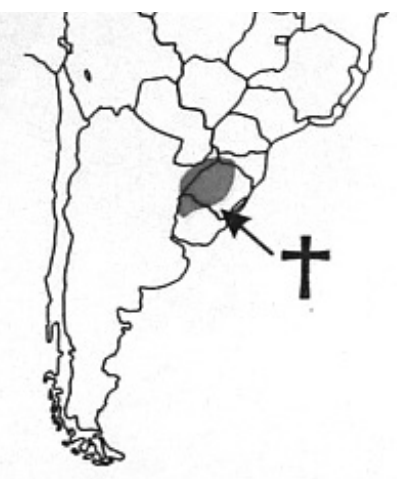

Figura 3: Distribuição de Anodhorhynchus glaucus (Fonte: Sigrist, 2005)

considerado Extinto regionalmente quando o mesmo estiver extinto no país (Brasil), mas existente em outras partes do mundo.

No contexto da categoria Extinta regionalmente, consideram-se espécies que estão sabidamente ou presumivelmente extintas num país, mas existentes em outras partes do mundo.Foi adicionada a extinção para estado (Brasil), sendo esta adaptação proposta por Gardenfors et al. (2001). Estudos sobre aves florestais especializadas, mostraram a relação entre extinção e fragmentação florestal tanto na Amazônia (Ridgely, 1989; Sick, 2001), como em mata atlântica (Ribon, 1998). Deve-se relatar que para a avifauna, no bioma de Mata Atlântica, várias espécies de aves são consideradas estáveis ou com densidades no padrão normal, mas ainda assim estão se tornando extintas em áreas fragmentadas (Brooks e Balmford, 1996; Goerck, 1997).

c) Extinta na natureza - Um táxon será considerado Extinto na Natureza quando é co- 
nhecido por sobreviver apenas em cativeiro, criação ou como uma população naturalizada fora de sua área original de ocorrência.

A categoria Extinta na natureza é aplicada a espécies existentes somente em cativeiro, criação ou como população naturalizada fora de sua área original de ocorrência. Essa categoria foi proposta visando identificar espécies potenciais de fauna ou flora, sensíveis a alterações ambientais e susceptíveis a projetos de conservação na natureza.

d) Ameaçada - é uma espécie cujas populações estão decrescendo a ponto de colocá-la em risco de extinção. É importante frisar que não há consenso claro sobre os critérios de inclusão de uma espécie na lista das ameaçadas. Há uma interpretação corrente de que a preservação de espécies ameaçadas é incompatível com a exploração econômica do ambiente em que vivem, que deveria ser preservado. Esse parâmetro é aplicável para alguns casos, mas não para todos. Observa-se, atualmente, um crescente uso de práticas de manejo conservacionistas do uso do solo visando sustentabilidade dos hábitats naturais.

Pode ser enquadrada em três níveis de ameaça:

- Criticamente em perigo - Táxon que corre um risco extremamente alto de extinção na natureza num futuro próximo, como definido pelos critérios de A a E da IUCN (2001)

- Em perigo - Táxon que corre um risco muito alto de extinção na natureza num futuro próximo, como definido por qualquer dos critérios $\mathrm{A}$ a $\mathrm{E}$ da IUCN (2001)

- Vulnerável - Táxon que corre um risco alto de extinção na natureza a médio prazo, como definido por um dos critérios de $\mathrm{A}$ a $\mathrm{E}$.

A categoria Criticamente em perigo inclui espécies com altíssimos riscos de extinção na natureza. Um exemplo desta categoria, é o primata bugio (Alouatta guariba guariba), da família Atelidae (figura 4). Trata-se de espécie restrita a regiões da Bahia e Minas Gerais, onde habitam exclusivamente as florestas do bioma Mata Atlântica. A principal ameaça à sua sobrevivência tem sido a destruição deste hábitat. As áreas de floresta são "recortadas" pelas cidades, restando apenas pequenas ilhas isoladas pela ocupação humana. A transformação das áreas de mata em loteamentos tem provocado o desaparecimento das espécies da flora e fauna silvestre, entre elas, o bugio. O isolamento das áreas de mata obriga os bugios a correrem riscos para se dispersarem. $\mathrm{O}$ bugio pode tentar atravessar uma área com ocupação humana para chegar a uma nova área de floresta. Se essa travessia for pelo alto das árvores e muito próxima a redes elétricas, podem ocorrer choques elétricos, mutilando ou levando esses animais à morte. Se for pelo solo podem acontecer incidentes como atropelamento, ataque por cães e conflitos com humanos.

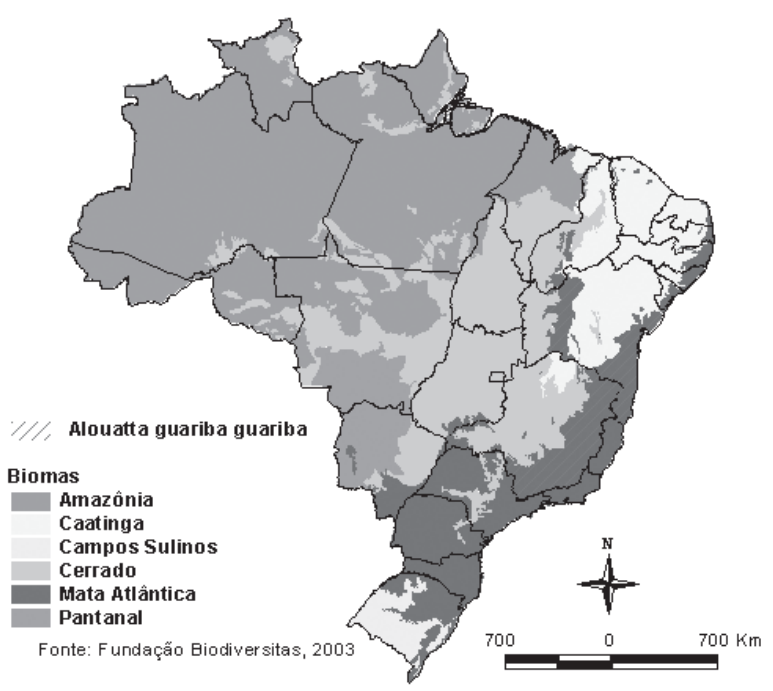

Figura 4: Distribuição de Alouatta guariba guariba

\footnotetext{
Grau de Ameaça: Criticamente em perigo

Critério: B2ab(i,ii,iii), C2a(i), D Data: 2003

Estados: BA, MG, Biomas: Mata Atlântica

Habitats: Floresta de terra firme, floresta montana

Mata Atlântica - endemica ao Brasil. Rylands et al. (1988) observaram grupos com dimorfismo sexual em uma área ao sul do rio Jequitinhonha em Minas Gerais, embora para o leste, próximo ao limite com a Bahia e também na margem sul daquele rio, os mesmos autores tenham encontrado grupos sem a presença de dimorfismo sexual. Do mesmo modo, Mendes (pers. obs.) observou grupos de A. fusca no norte do Espírito Santo com as características da subespécie clamitans. A forma A. f. fusca, se válida, provávelmente, se restringe a uma área de ocorrência muito menor do que se supunha previamente: sul da Bahia e norte de Minas Gerais, na região do rio Jequitinhonha (Coimbra-Filho, 1972; Santos et al., 1987; Rylands et al., 1988; Oliver \& Santos, 1991).
} 
A categoria Em perigo, inclui espécies com altos riscos de extinção na natureza. São exemplos dessa classificação: mico-leão-de-cara-dourada (Leontopithecus chrysomelas) (figura 5) e sagui da serra (Callithrix flaviceps). A primeira espécie L. chrysomelas, apresenta hábitos noturnos, arbóreo, vive em grupos de 2 a 5 indivíduos. Se alimenta de frutos, insetos e néctar. Podem ser encontrados no interior de florestas, mas mostram-se mais comuns em áreas densas com trepadeiras, como bordas de rios e áreas abertas. São considerados sedentários, uma vez que se deslocam pouco. São uns dos primatas mais comuns em áreas próximas a povoados. Ocupam amplas áreas de florestas maduras, perturbadas e secundárias, desde a floresta tropical chuvosa até as matas secas do Chaco (Emmons, 1990).

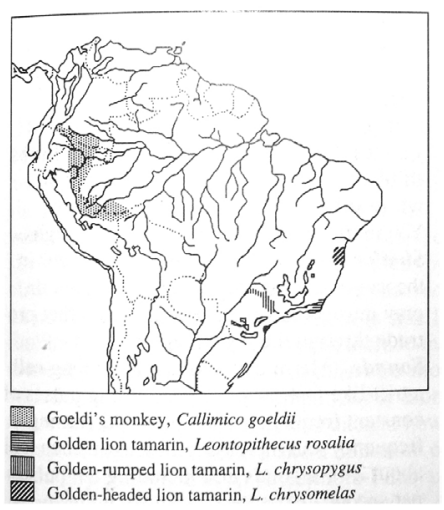

Figura 5: Distribuição de Leontopithecus chrysomelas Fonte: Emmons, 1990

A categoria Vulnerável apresenta causas de redução reversíveis, bem conhecidas e já ausentes; taxa de redução de $50 \%$ em dez anos ou em três gerações e assim como para as categorias Criticamente em Perigo e Em Perigo.

Esses parâmetros devem ser observados dentro de metodologias específicas (incluindo análise qualitativas e quantitativas) em projetos de conservação em locais específicos com profissionais especializados em cada grupo. Dessa forma é possível obter registros precisos para gerar relatórios acurados com informações reais da atual situação da espécie, das relações fauna-flora, da influência dos impactos ambientais diretos, indiretos, da temporalidade desses impactos, da frequência desses impactos e da situação local e regional. Essa categoria inclui espécies que correm altos riscos de extinção devido à alta sensibilidade a alterações ambientais como processos de fragmentação e destruição de habitats. É o caso de espécies extremamente raras como cuíca-de-colete (Caluromysiops irrupta) (figura 6), cuja densidade populacional no ambiente é estimada em valores menores que 30 indivíduos. Trata-se de marsupial noturno, arbóreo, solitário que, na estação seca se alimente de néctar, mas também inclui frutos na dieta. (Emmons, 1990). Esta espécie encontra-se restrita ao estado de Rondônia e sujeita a entrar na lista de Extinta regionalmente caso não seja implementado um programa de conservação).

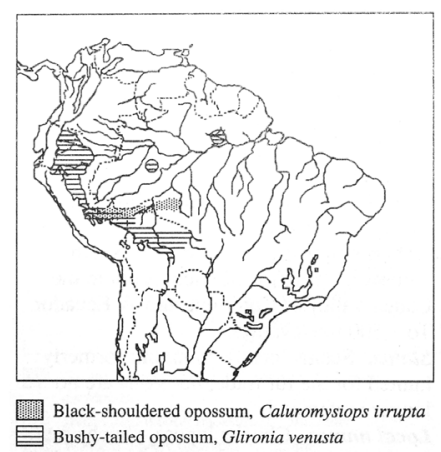

Figura 6: Distribuição de Caluromysiops irrupta Fonte: Emmons, 1990

Dentre as espécies de fauna vulneráveis, observa-se mamíferos da Ordem Carnívora e Famílias Canidae como Lobo-guará (Chrysocyon brachyurus) (figura 7), Cahorro vinagre (Speothos venaticus) (figura 8), Felidae como onça-pintada (Panthera onca), Onça parda (Puma concolor) e Jaguatirica (Leopardus pardalis), Gato maracajá pequeno (Leopardus tigrinus) e Gato maracajá peludo (Leopardus tigrinus). 


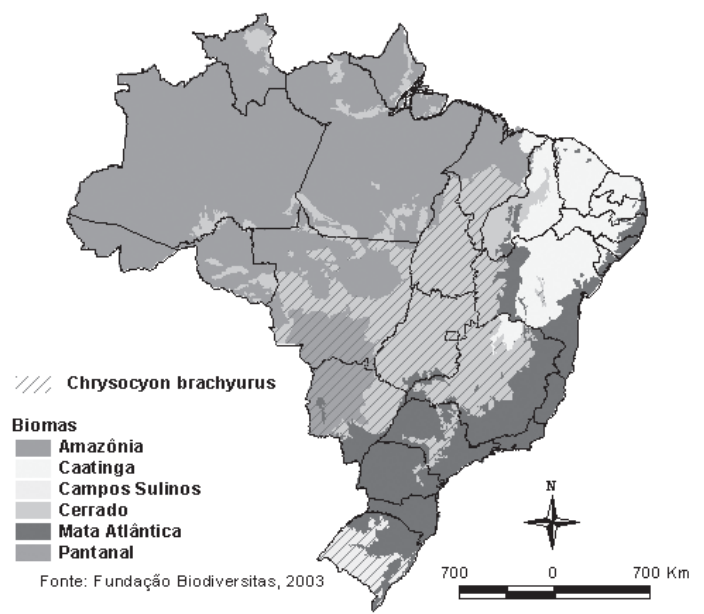

Figura 7: Distribuição de Chrysocyon brachyurus

Estados: BA, DF, GO, MA, MG, MS, MT, PR, RJ, RS, SC, SP, TO Biomas: Campos Sulinos, Cerrado, Pantanal

Habitats: Todas as fisionomias de Cerrado, campos sulinos, chaco e outros ambientes abertos.

Habita campos e Cerrados do centro da América do Sul, da foz do Rio Parnaíba no nordeste do Brasil, sul pelo Chaco do Paraguai até o Rio Grande do Sul e oeste até o extremo leste do Peru. Beccaceci (1992) achou evidência de lobos na Argentina no paralelo $30^{\circ}$, e um avistamento na província de Santiago del Estero foi publicado recentemente. Eles provavelmente ocorrem no norte do Uruguai. A presença neste país foi confirmada por um espécime capturado em 1990 (Mone \& Olazarri 1990), mas não houve qualquer relatório de vistas desde aquela data (S.O. González com. pess.).

As espécies L. wiedii e L. tigrinnus, apesar de presentes em vários estados no Brasil, mostram-se cada vez mais raros devido aos processos de fragmentação florestal, expansão agrícola, caça predatória, redução da disponibilidade de recursos alimentares e acidentes em rodovias. Não apresentam grandes populações (acima de 30 indivíduos) e capacidade reprodutiva associada à qualidade do hábitat.

e) Quase ameaçada - Táxon que não atinge mas está próximo de atingir os critérios de ameaça, ou provavelmente estará ameaçado em um futuro próximo. Em relação a esta categoria podemos citar aves representantes da família Cotingidae, como anambé de asa branca Xipholena atropurpurea (figura 9). Trata-se de espécie endêmica do Brasil oriental, encontrada nas matas de tabuleiro, na hiléia baiana e na Mata Atlântica, entre 0 m e 900 m de altitude, muito embora seja comum em florestas úmidas de baixada litorâ-

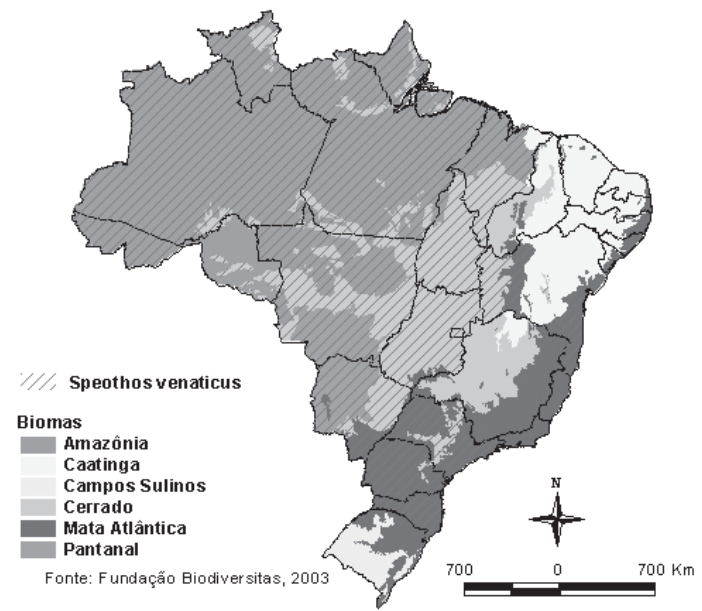

Figura 8: Distribuição de Speothos venaticus

Estados: BA, DF, GO, MA, MG, MS, MT, PR, RJ, RS, SC, SP, TO Estados: AC, AM, AP, BA, DF, GO, MA, MS, MT, PA, PR, RO, RR, $\mathrm{SC}, \mathrm{SP}, \mathrm{TO}$

Biomas: Amazônia, Cerrado, Mata Attântica, Pantanal

Habitats: Floresta tropical, subtropical, premontana, ombrófila, decidual, semidecidual, Cerrado, Pantanal, sempre na proximidade de cursos d'água, região Amazônica tendo como limite leste o Rio Parnaíba, Brasil Central até norte de Santa Catarina

nea. Alimenta-se de frutos e poucos insetos. Observa-se comportamento de formação das fêmeas do anambé em bandos mistos com outros frugívoros. A espécie sofre ameaça da perda do hábitat, embora possa se tornar comum em matas secundárias devido à frutificação sazonal de certas plantas.

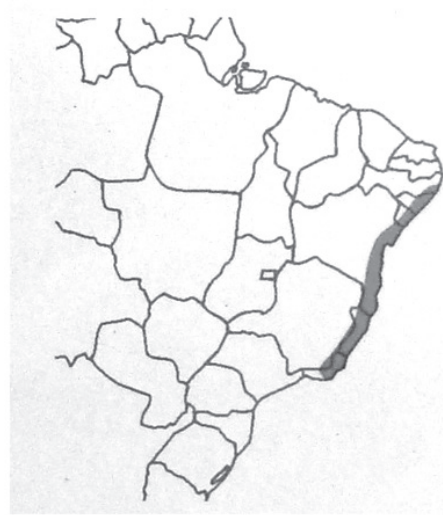

Figura 9: Xipholema atropurpurea Fonte: Sigrist, 2005 
f) Não ameaçada - Táxon que foi avaliado quanto ao seu risco de extinção, mas não se enquadrou em nenhuma das categorias de ameaça da IUCN (2001)

Um exemplo típico desta categoria é a espécie surucuá-variado (Trogon surrucura) Trogonidae (figura 10). Trata-se de espécie encontrada em áreas montanhosas de até 2000 $\mathrm{m}$ de altitude no Sudeste e Sul do Brasil. Vive no estrato médio e nas copas em matas primárias e secundárias altas, em matas de araucária, em cerradões, podendo sobreviver em áreas perturbadas. Dieta onívora, que inclui frutos, lagartas, moscas, aranhas e outros artrópodes.

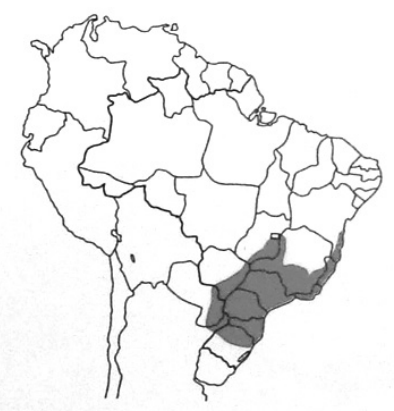

Figura 10: Trogon surrucura

Fonte: Sigrist, 2005

g) Dados insuficientes - Sem dados suficientes para enquadramento em alguma das categorias acima. Essa categoria engloba espécies pouco descritas ou sem registro preciso de localização, número de indivíduos ou ainda classificação precisa. Um exemplo importante é a espécie tiê-bicudo (Conothraupis mesoleuca) Thraupidae, extremamente raro, coletado apenas no século XIX em matas secas da Chapada dos Parecis, MT (figura 11). A espécie, considerada extinta, habitava o cerradão, tendo preferência por áreas mais alagadas. Sem ser vista há 66 anos, foi redescoberta no Cerrado, no estado de Goiás, por Dante Buzetti, no Parque Nacional das Emas em 2006. Durante esse registro, foi registrada a vocalização da espécie, fato inédito até o momento (Folha de São Paulo 03/05/06).

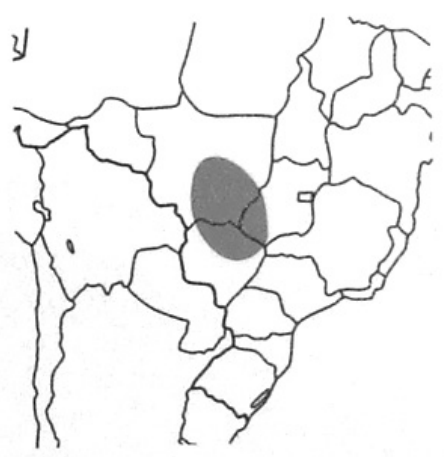

Figura 11: Conothraupis mesoleuca Fonte: Sigrist, 2005

A espécie maria preta do nordeste (Knipolegus franciscanus)Tyrannidae (figura 12), é endêmica. Ocorre no Nordeste e no Brasil Central, nas caatingas e áreas com lajedos e enclaves rochosos adjacentes dos rios do Vale do São Francisco, em Minas Gerais. Em trabalho de levantamento de avifauna na região de Jequitaí, em 2004, foi observado um indivíduo em enclave de caatinga, ao norte do município de Jequitaí, sendo devidamente registrado e georreferenciado o local de observação.

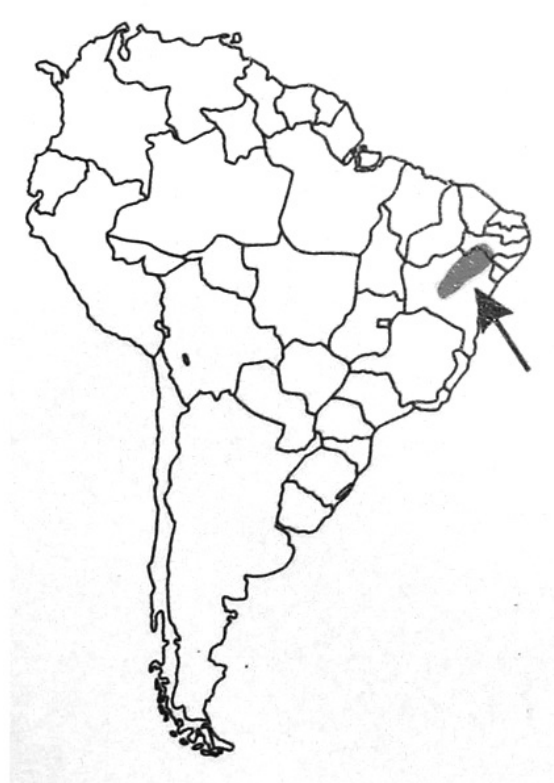

Figura 12: Knipolegus franciscanus Fonte: Sigrist, 2005 
A espécie cara-dourada (Phyllocartes roquetei) Tyrannidae (figura 13), é considerada endêmica, sendo descrita apenas em 1928, em florestas tropicais secas, matas de galeria e áreas com lajedos e enclaves rochosos adjacentes aos rios do Vale do São Francisco, em Minas Gerais. A espécie encontra-se ameaçada pela perda do hábitat.

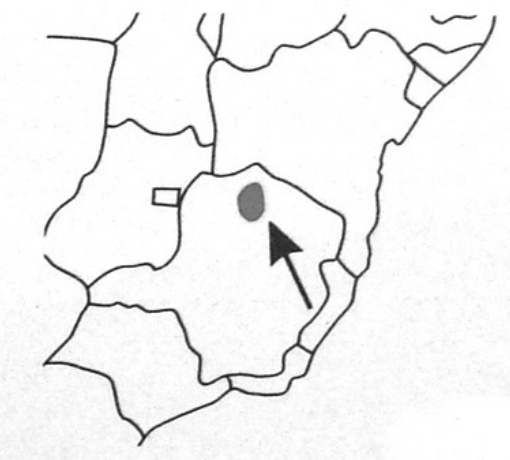

Figura 13: Phyllocartes roquetei Fonte: Sigrist, 2005

A espécie cara pintada (Phyllocartes ceciliae) Tyrannidae (figura 14), é endêmica e foi recentemente descrita habitando as florestas residuais montanas de Alagoas em altitudes entre $400 \mathrm{~m}$ e 500 $\mathrm{m}$. Atualmente encontra-se ameaçada pela perda do hábitat.

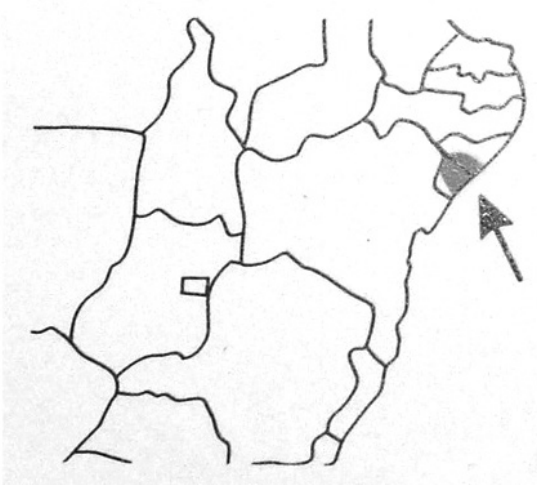

Figura 14: Phyllocartes ceciliae

Fonte: Sigrist, 2005
Há ainda alguns outros critérios para caracterizar de maneira mais eficiente o atual estado de distribuição do taxa de interesse:

Em relação ao critério População em declínio, deve-se amostrar a espécie em estudo, de forma a levantar dados objetivos e corretos da atual situação da população ou das populações. É fundamental a informação de levantamentos anteriores, para se basear os estudos da ecologia populacional, sendo importante registrar os agentes causais e os impactos ambientais nas áreas de ocorrência, os tipos de impactos ambientais, a incidência do impacto, a situação, a temporalidade, a severidade, a abrangência e a freqüência. Dessa maneira, é perfeitamente possível realizar uma análise acurada da classificação da população dentro de uma categoria segundo as normas da IUCN.

Para o critério Distribuição restrita e declínio ou flutuação, espécies com distribuição menor que $20000 \mathrm{~km}^{2}$, devem ser enquadradas na categoria Vulnerável; espécies com distribuição menor que 5000 $\mathrm{km}^{2}$, devem ser enquadradas na categoria Em perigo; espécies com distribuição menor que $100 \mathrm{~km}^{2}$, devem ser enquadradas na categoria Criticamente em perigo. Esse critério está diretamente relacionado com espécies que apresentam distribuição peculiar, como a rara saíra-apunhalada (Nemosia rourei) Thraupidae (figura 15), espécie de dossel, típica de floresta serrana, em altitudes que variam de $900 \mathrm{~m}$ a $1100 \mathrm{~m}$ de altitude e restrita aos estados de Minas Gerais e Espírito Santo. Outra espécie também rara, cara-pintada (Phylloscartes ceciliae) (figura 16), Tyrannidae, recentemente descrita em florestas residuais montanas do estado de Alagoas, em altitudes entre $400 \mathrm{~m}$ e 500 $\mathrm{m}$, restrita a ambientes de copas e bordas de floresta serrana e considerada endêmica ( $\mathrm{Si}$ grist, 2005). Esta última encontra-se ameaçada pela perda de hábitat. 


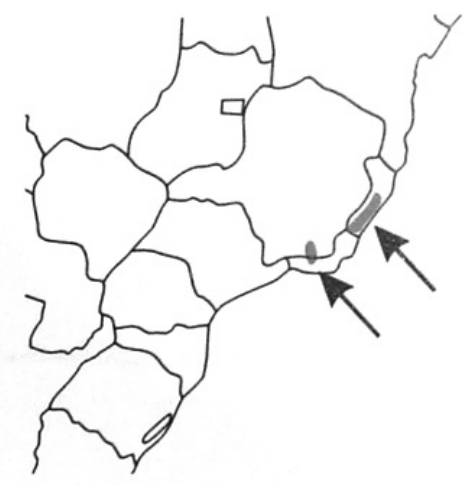

Figura 15: Nemosia rourei

Fonte: Sigrist, 2005

Para o critério Tamanho populacional reduzido e em declínio, sugere-se que as espécies de uma dada população encontram-se sob efeito de atributos ecológicos e físicos desfavoráveis, não se mostrando adaptadas para adquirir crescimento desejado para evitar a extinção. Esse critério pode ser exemplificado para a espécie polícia-inglesa-do-norte (Leistes militaris), Icteridae (Globalmente ameaçada) (figura 17), presente na amazônia, em áreas abertas ou paludícolas, campos, pastagens e ilhas fluviais, fazendas e áreas de campinarana. Observa-se flutuação das populações em certos locais, provavelmente devido a destruição de hábitat (Sigrist, 2005).

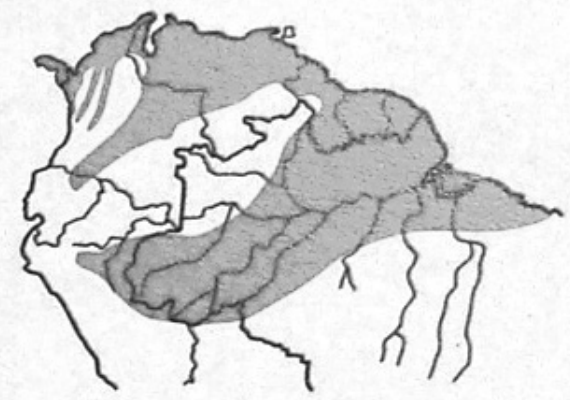

Figura 17: Leistes militaris

Fonte: Sigrist, 2005

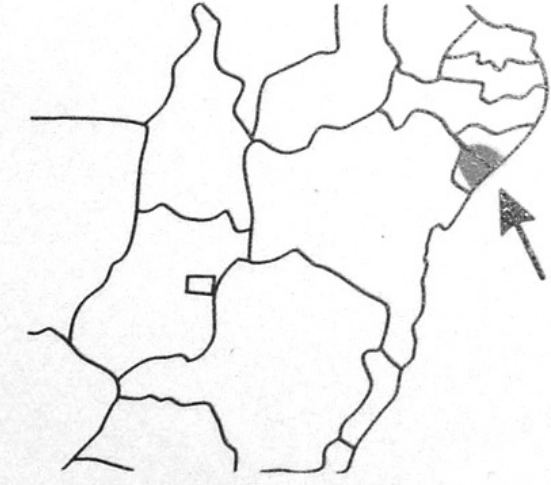

Figura 16: Phylloscartes ceciliae

Fonte: Sigrist, 2005

Para o critério Tamanho populacional reduzido e restrito, sugere-se que as espécies de uma dada população encontram-se sob efeito de atributos ecológicos e físicos intensos e limitantes, se mostrando restritas áreas de ocorrência. Processos subseqüentes de destruição de hábitats por ação antrópica, provavelmente irão eliminar tal população do ambiente. Dessa forma, pode-se observar a tendência de mudança de categoria da espécie. Um exemplo importante para esse critério é a maria-preta-de-asa-branca (Knipolegus franciscanus) Tyrannidae. Esse critério pode ser exemplificado pela espécie tiriba-grande (Pirrhura cruentata), Psittacidae (figura 18), espécie endêmica ameaçada, que habita copas de florestas altas, é encontrada da Mata Atlântica Montana às florestas úmidas das baixadas litorâneas, em matas de tabuleiros e na hiléia baiana ao norte do Rio de Janeiro até o sul da Bahia, entre 0 a 400 $\mathrm{m}$ de altitude. Raramente alcança os $920 \mathrm{~m}$ no interior de Minas Gerais. Outro exemplo específico é o furnarídeo joão-lenheiro ( $A s$ thenes luizae) (figura 19), espécie endêmica dos campos rupestres de Minas Gerais (Serra do Cipó) entre $900 \mathrm{~m}$ e $1500 \mathrm{~m}$ de altitude. A espécie forrageia na vegetação arbustiva ou em lajedos rochosos típicos do biótopo. 


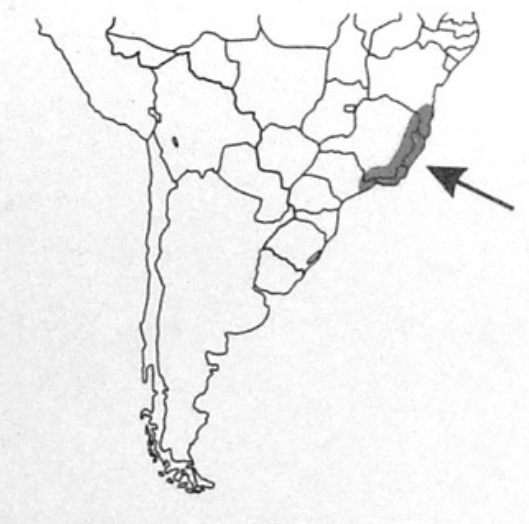

Figura 18: Pirrhura cruentata

Fonte: Sigrist, 2005

A espécie balança rabo canela (Glaucis dohrnii), Trochilidae (figura 20), é endêmica ameaçada, que habita matas de tabuleiros e da hiléia baiana entre o Espírito Santo e o sul da Bahia. Freqüenta mata primária e bordas de matas secundárias adjacentes. Esta rara espécie sobrevive em uns poucos remanescentes florestais pouco protegidos pelo estado. (Sigrist, 2005).

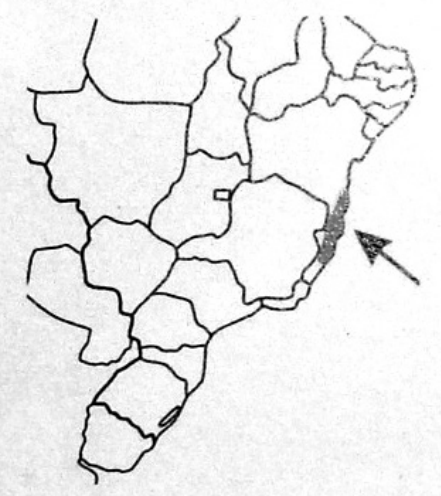

Figura 20: Glaucis dohrnii

Fonte: Sigrist, 2005

Para o critério Análise quantitativa mostrando a probabilidade de extinção na natureza, calculo do $\mathrm{n}^{0}$ de indivíduos, deve-se proceder o uso de Método de Amostragem por Pontos (Blondel et al., 1970; Vielliard \& Silva, 1990). Desta for-

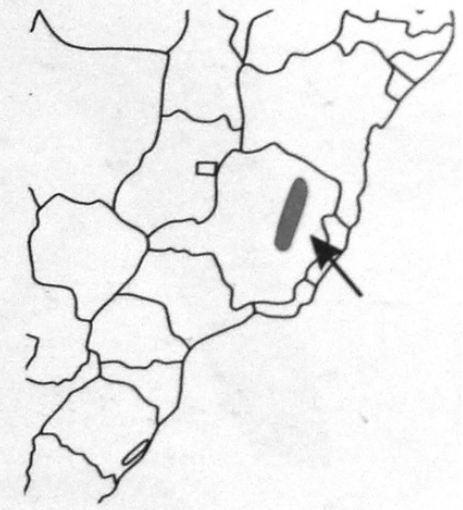

Figura 19: Asthenes luizae

Fonte: Sigrist, 2005

ma, sempre que possível, serem registradas as vocalizações com gravador Sony TCM$-5000 \mathrm{EV}$ e microfone direcional Sennheiser ME66. As observações devem ser feitas em campanhas de campo de 10-15 dias, contabilizando o total de horas de esforço amostral. Devem ser utilizados binóculos $8 \times 40$ $\mathrm{mm}$. O processo de observação deve-se iniciar às 5:00 da manhã terminando por volta das 8:00 horas e no período de 16:00 às 20:00, para levantamento de aves de hábitos crepusculares e noturnos. A documentação das espécies pode ser feita em planilha de campo com informações relativas ao horário, espécie, sexo, comportamento, ambiente, etc. Pode-se utilizar de fotografias com máquinas digitais, com zoom óptico mínimo de $20 \mathrm{x}$. Deve-se ainda proceder o uso de redes de neblina, conforme metodologia proposta por Foster \& Cannell (1990), Vuilleumier (1998, 2000). Os exemplares capturados devem ser pesados, sexados, devem ser realizadas medições de asas, bicos e tarsos e posteriormente anilhados. Deve-se aplicar estratégias de armação de redes de neblina para cada situação específica. Em caso de floresta primária, deve-se caminhar inicialmente pela área, em horário de deslocamento de espécies, tanto pelas bordas dos fragmentos, como pelo seu interior. As 
redes devem ser armadas de acordo com a observação prévia do especialista, levando em consideração os possíveis tipos de ocorrência na região. As redes $(3,0 \mathrm{~m}$ x $12,0 \mathrm{~m}$ de $26 \mathrm{~mm}$ ) poderão ser armadas ao nível do solo, até $3 \mathrm{~m}$ de altura, visando capturar representantes das Famílias Formicariidae, Tyrannidae e Thraupidae que forrageiam na serrapilheira. Redes armadas no limite do estrato baixo para o estrato médio ( $4 \mathrm{~m}$ a 8 $\mathrm{m}$ de altura) podem capturar representantes das famílias Thraupidae, Dendrocolaptidae, Trogonidae, Momotidae e Cuculidae. Redes armadas no estrato alto (acima de $10 \mathrm{~m}$ de altura) podem capturar representantes das famílias Tyrannidae, Thraupidae, Thamnophilidae, Trogonidae. As espécies devem ser classificadas de acordo com o grau de endemismo e/ou estado de conservação segundo Cracraft (1985), Silva (1995a e b), Ridgely e Tudor (1989, 1994), Machado et al. (1998), Statterfield et al. (1998) e BirdLife International (2000, 2004).

Para o estado do Pará, está sendo proposta uma lista de espécies candidatas a ameaça. É com base nestas informações que será formulada a lista oficial de espécies da fauna e flora ameaçadas de extinção.

Foram consideradas candidatas a integrarem a lista de espécies ameaçadas do Pará aquelas espécies e subespécies com ocorrência comprovada no estado e que obedeciam a pelo menos um dos seguintes critérios:

1) consideradas ameaçadas ou quase ameaçadas pela IUCN (http://www. redlist.org);

2) constantes na lista mais recente das espécies brasileiras ameaçadas de extinção (http://www.mma.gov.br/port/ sbf/fauna/index.cfm);

3) espécies e subespécies com ampla distribuição, mas que sofrem pressão de caça ou exploração predatória comercial;

4) espécies e subespécies endêmicas dos centros de endemismo Belém e Pará, localizados predominantemente em território Paraense, e que sofrem forte impacto antrópico por se encontrarem na região conhecida como "arco de desmatamento";

5) espécies raras, potencialmente ameaçadas ou com distribuição restrita na região Amazônica.

\section{CONCLUSÃO}

A própria IUCN sugere que as atuais categorias para inclusão das espécies devem ser substituídas por sistemas de avaliação mais rigorosos, uma vez que não é possível reavaliar todas as espécies com edições antigas, de 10 anos ou 5 anos passados. As futuras edições serão realizadas e disponibilizadas (caso da lista da IUCN 2010) e comparadas com as listas anteriores para mensurar a situação atual de cada grupo e permitir discutir os parâmetros globais, regionais e as vezes locais para cada grupo que envolvem a distribuição, freqüência e densidade, para sugerir medidas conservacionistas para manutenção da biodiversidade. Essas medidas devem ser executadas rapidamente, tendo em vista às atuais condições dos processos de degradação ambiental observados no planeta atualmente, principalmente em áreas tropicais.

\section{REFERÊNCIAS BILIOGRÁFICAS}

BECCACECI M.D. The maned wolf, Chrysocyon brachyurus, in Argentina in B. MATERN (Ed.), 1991. International studbook for the maned wolf Chrysocyon brachyurus (Illiger, 1811). Frankfurt Zoological Garden, Frankfurt, Germany, p 50-56, 1992.

BIRDLIFE INTERNATIONAL. State of the world's birds 2004: indicators for our changing world. Cambridge, UK: BirdLife International, 2004. 
BIRDLIFE INTERNATIONAL. Lynx Edicions e BirdLife International, 852p., 2000.

BROOKS T.; BALMFORD, A. Atlantic forest extinctions. Nature, 380: 115, 1996.

COIMBRA-FILHO, A.F. 1972. Mamíferos ameaçados de extinção no Brasil. In: Academia Brasileira de Ciências. Espécies da Megadiversidade: fauna brasileira ameaçada de extinção, Academia Brasileira de Ciências, Rio de Janeiro, 1, 1, pp.13-98, julho 2005.

CRACRAFT, J. Historical biogeography and patterns of differentiation within the South American avifauna: areas of endemism. Ornithological Monographs, Lawrence, v. 36, p. 49-84, 1985.

Emmons, L.H. Neotropical Rainforest Mammals: A field guide. The University Press.Chicago, 298 p., 1990.

BUZETTI, D. Considerada extinta reaparece em Goiás Folha de São Paulo, São Paulo, 03/05/2006 (v ersão online) disponível em http://www 1.folha.uol.com.br/fsp/cotidian/ ff0305200617.htm. Acessada em 20/04/2010.

FOSTER, M. S.; CANNELL, P. F. Bird specimens and documentation: critical data for a critical resource. The Condor, v. 92, p. $277-$ 283, 1990.

GARDENFORS, U.; HILTON-TAYLOR, C.; MACE, G.M. \& RODRIGUEZ, J.P. 2001. The application of IUCN Red List Criteria at regional levels. Conservation Biology, v.15, n. 5, p. 1206-1212, 2001.

GOERCK, J.M. Patterns of rarity in the birds of Atlantic forest of Brazil. Conservation Biology, v. 11, p. 112-118, 1997.

http://www.mma.gov.br/port/sbf/fauna/index.cfm);
IUCN. IUCN Red List Categories and Criteria: version 3.1. Gland e Cambridge, IUCN-Species Survival Commission. ii +32 pp, 2001.

MACHADO , A. B. M., FONSECA, G. A. B., MACHADO, R. B., AGUIAR, L. M. S.; LINS, L. V. Livro vermelho das espécies ameaçadas de extinção da fauna de Minas Gerais. Belo Horizonte: Fundação Biodiversitas, 608p., 1998.

MONES, A.; OLAZARRI, J. Confirmación de la existencia de Chrysocyon brachyurus(Illiger) en el Uruguay (Mammalia: Carnivora: Canidae). Comunicaciones Zoológicas del Museo de Historia Natural de Montevideo, v. 174, n. 7, p.1-6, 1990.

OLIVER W.L.R.; SANTOS. B. Threatened endemic mammals of the Atlantic Forest region of south-east Brazil. Jersey Wildlife Preservation Trust, Jersey. 126 p., 1991.

RIBON, R. Fatores que influenciam a distribuição de avifauna em fragmentos de Mata Atlântica nas montanhas de Minas Gerais. Tese mestrado. Universidade Federal de Minas Gerais, Belo Horizonte, Brasil. 128 p., 1998.

RIDGELY, R.S., TUDOR, G. The Birds of South America, Volume 2, the Suboscine Passerines. Oxford University Press, UK. 516 p., 1994.

RIDGELY, R.S., TUDOR, G. The Birds of South America, Volume 1, the Oscine Passerines. Oxford University Press, UK. 814 p., 1989

RYLANDS, A. B. ; SPRIRONELO, W. ; KIERULFF, M. C. M. ; SANTOS, I. B. Primates of the Rio Jequitinhonha valley, Minas Gerais, Brazil.. Primate Conservation, Washington, DC, v. 9, p. 100-109, 1988. 
SANTOS, I.B., MITTERMEIER, R.A., RYLANDS, A.B., and VALLE, C.M.C. The distribution and conservation status of primates in southern Bahia, Brazil. Primate Conservation, v. 8, p. 126-42, 1987.

SICK, H. Ornitologia brasileira. Rio de Janeiro: Nova Fronteira, 912 p., 2001.

SIGRIST. T. Aves do Brasil: uma visão artística. São Paulo: Fosfértil, 672 p., 2005.

SILVA, J. M. C. Biogeographic analysis of the South American Cerrado avifauna. Steenstrupia, Copenhagen, v. 21, p. 49-67, 1995a.

SILVA, J. M. C. Birds of the Cerrado region, South America. Steenstrupia, Copenhagen, v. 21, p. 69-92, 1995 b.

STATTERSFIELD, A. J.; CROSBY, M. J.; LONG, A. J.; WEGE, D. C. Endemic bird areas of the world: priorities for biodiversity conservation. Cambridge: BirdLife International, 846p, 1998.
UICN (http://www.redlist.org);

VIELLIARD, J.M.E. \& W.R. SILVA. Nova metodologia de levantamento quantitative da avifauna e primeiros resultados do interior do Estado de São Paulo, Brasil. In: Anais do IV Encontro Nacional de Anilhadores de Aves, Recife, p. 117-151, 1990.

VUILLEUMIER, F. 1998. The need to collect birds in the Neotropics. Ornitologia Neotropical, v. 9, p. 269-274, 1998.

VUILLEUMIER, F. Response: further collecting of birds in the Neotropics is still needed. Ornitologia Neotropical, n 11, p. 201203, 2000. 